\title{
ARTICLE \\ Uses of Different Techniques for the Production of Sustainable Soil and Food
}

\section{Sahrish Khan*}

Department of Biotechnology, Quaid-i-Azam University Islamabad, Pakistan

\section{ARTICLE INFO}

Article history

Received: 28 August 2020

Accepted: 17 September 2020

Published Online: 30 September 2020

Keywords:

Sustainable soil

Food

Genetic engineering

Nanotechnology

Bioremediation

\begin{abstract}
Due to the rapid increase in population, it is estimated that the human population will increase to 9.7 billion in 2050 . Hence the demand for food production will also increase. That is why there is a need to solve problems regarding food production. Major problems in food production are the shortage of land due to bad soil structure and quality of the soil. Soil erosion is one of the major issues caused by the use of different chemicals, pesticides and fertilizers that mainly used for plant growth and protection, but at the same time, they also pollute the soil. Therefore, new technology is needed for improving the soil structure, quality, fertility and its decontamination, that should be eco-friendly having no adverse effects on the environment. In this study, the role of different techniques like genetic engineering, Nanotechnologies, soil and crop management strategies, integrated pest control management strategies, sustainable remediation techniques, microbial management strategies and the different management strategies are taken into account. All these techniques aim to produce plants and microbes that are effective against plant disease management. The aim is to use nano agrochemicals and nanosensors for sensing environmental and pathogen conditions against disease management. The primary purpose is to develop disease resistance in plants and to provide balanced nutrient supplements to the soil for the improvement of soil condition and its fertility. These techniques are of economic importance owing to the use of the nano agrochemicals that have low cost, are more effective and also reduce the use of chemical substances that have an adverse effect on soil fertility. Many sustainable remediation techniques used for decontamination of soil are also discussed. The main focus of this study is to improve and increase soil fertility for enhancing the growth of the plants as well as the production of crops. Stress and degradation resistance microbes are found to be essential factors for the protection of soil from degradation or contamination in this study. All the techniques which are used in this paper have no adverse effect on the environment and are also helpful in developing stress resistance.
\end{abstract}

*Corresponding Author:

Sahrish Khan,

Department of Biotechnology, Quaid-i-Azam University Islamabad, Pakistan;

Email:sahrishkhan727@gmail.com 


\section{Introduction}

$\mathrm{N}$ utritional deficiency due to the shortage of food supply has to descend to 1 billion in $2009^{[1]}$ from 850 million ${ }^{[2]}$, which is alarming. Statistics have revealed that frailty development in people due to lack of food availability has increased to 263 million for South Asia (SA), 212 million in sub-Saharan Africa (SSA), 268 million in China and Southeast Asia, 60 million in South and Central America and the Caribbean and 50 million for rest of the world. The most significant contributing factor that is often ignored in this regard is soil richness ${ }^{[3]}$. In contrast to other business, horticulture needs more attention, efforts and hard work ${ }^{[4]}$.

Due to the increase in the population, the demand for food is also increasing, as the estimated population growth by 2050 is 9.7 billion. To meet food demand of the growing population, food production will have to be increased by $50 \%$. Keeping this in mind, there is a need to devise techniques to resolve the issues related to food production ${ }^{[5]}$. Food protection and the development of sustainable food resources offer a new challenge due to depletion of natural resources because of soil contamination, environmental pollution and species extinction ${ }^{[6]}$.

For the production of food, water availability and soil quality are major factors. This cultivable land covers around $12 \%$ area of earth' area ${ }^{[7]}$. Soil degradation is one of the major issues present in many regions of the world. Soil contamination removes 75 billion tons of soil per year. Soil contamination affects nearly $80 \%$ of cultivated land due to improper agriculture practices ${ }^{[8]}$ which in turn has a negative impact on food production ${ }^{[9]}$. For the production of food, the improvement of soil condition is needed, which in turn is a big challenge because of the increasing population.

The organic content of soil decreases due to soil erosion which is responsible for the reduction in hydrolytic properties of soil and also affects the soil water holding capacity and its stability. Development of successful strategies of soil management and productivity of agriculture requires improvement and maintenance of efficient nutrient cycle and soil organic matter. These practices make use of fertilizers which also play an essential role in crop production ${ }^{[8,9]}$.

Different organic resources are used for the improvement of soil fertility and play an essential role in the growth of plants and the high yield of the crop. There are different techniques which are used for the production of sustainable soil and food. When soil fertility is right, then ultimately the productivity of food is also good. The soil has a significant impact on the productivity of food. For the production of sustainable food, there is a need to determine efficient resources ${ }^{[10]}$.

Different practices that are being carried out including the use of chemicals, fertilizers and pesticides negatively affect soil's quality that's why there is need of ecofriendly resources for the improvement of soil quality, making it a healthy medium for food production ${ }^{[1]}$. The use of microbial inoculants as an alternative of chemicals maintain soil's integrity as well as improves plant growth providing sustainable means agriculture ${ }^{[12,13]}$.

Different genetic modification techniques are being practised including horizontal gene transfer technique which involves the transfer of the genetic material between different microbes and making them more efficient through conjugation, transformation and transduction for the exchange and transfer of different genes which in turn play an important role in the improvement of soil fertility and production of the crop ${ }^{[14]}$.

\section{Use of Different Approaches for the Production of Sustainable Soil and Food}

There are different techniques which are used for the production of sustainable soil and sustainable food. These techniques play an essential role in the improvement of soil condition and growth of plants which are responsible for high crop yield, whereas soil erosion reduces food productivity and nutrient content of the soil.

\subsection{Genetic Engineering Techniques}

Different bacterial species are present in the root of plants increasing soil fertility and plant health, including tolerance against extreme climatic conditions. These bacterial communities evolve through the mobile genetic elements participating in the exchange and transfer of genetic material. They are used as a vector in the process of (HGT) horizontal gene transfer via transformation, transduction and conjugation, which make the bacteria more tolerant against stress conditions. These modifications occur by the expression of genes acquired through conjugative plasmids and other genetic elements ${ }^{[15]}$.

Genetically modified microbes, as well as genetically modified plants, play an essential role in the sustainable production of soil which makes plants more resistant against pests and insects and also increases the productivity of sustainable food. Contaminant degradative genes transferred to rhizosphere lead to improved plant growth ${ }^{[16]}$. Gene transfer in soil system as well in biofilms has been reported. All these gene transfer techniques enhanced the soil-plant-microbes relationship ${ }^{[17]}$. 
Different transgenic crops are monitored for the horizontal gene transfer from crop to soil microbes which have two implication for the field trial assessments in which plant to soil microbes horizontal gene transfer still have an environmental impact as well as present methods which are used for capturing traits and sampling in recombinant are insensitive for monitoring of the evolution of horizontal gene transfer. The HGT model involving short summarized events explains how HGT can occur at high frequencies but seen at relatively low frequencies ${ }^{[18]}$.

Genetic engineering techniques are used for the production of genetically modified crops which play an essential role in the production of food. Genetically modified crops are resistant to targeted pathogenic disease. Due to these modified crops, the need for pesticides is also reduced. Genetic engineering provides one to one basis for improving the stability of plant disease management. GE has beneficial effects for the long term and sustainable production of crops ${ }^{[19]}$.

\subsection{Effects of GM Crops on Rhizosphere Soil Bacteria}

Hereditarily adjusted plants can conceivably modify soil microbial networks and thus imperative environment capacities, including carbon cycling, nutrient solubilization and the occurrence of soil-borne plant malady ${ }^{[20]}$. Be that as it may, it is not evident whether these effects are straightforward because of the recently acquainted quality or by implication due to the change of the rhizosphere science of the GM plants.

Numerous constituents of soils, particularly colloidal particles including dirt minerals and sticky substances, have a high capacity to adsorb organic atoms, for example, DNA and proteins starting from soil microorganisms ${ }^{[21]}$. Growing logical proof show that dirt would safe be able to monitor such bioparticles from natural disintegration ${ }^{[22]}$. Consequently, the soil colloidintervened security component may empower soils to retain concerning specific molecule's genetic and toxic properties for a long time ${ }^{[23]}$.

In creating countries, GM crops can satisfy the food request of an ever-developing population and make nations independent in horticultural creation While a few investigations demonstrated that GM plants caused consider capable changes in the structure and elements of indigenous soil microbial network, the dirt heterogeneity, fluctuating dietary prerequisites of GM plants lack of appropriate controls and other environmental set-up forced significant challenges in deciphering the genuine effect of GM plants on soil microorganisms ${ }^{[24]}$.

\subsection{Nano-technologies}

There are different nano-based which alternative to other conventional technologies. For production and protection of plant and crops yield, there are different nano-enabled agrochemicals and nanosensors are used. Different nanosensors are used for the sensing undesirable conditions of plants due to pathogens and stress factors ${ }^{[25]}$.

There are different agrochemicals used for protection and production of crops yield. These agrochemicals have industrial importance due to their low cost and also have importance to increase productivity. These agrochemicals are sprayed on leaves of young plants of potatoes as well as on (eggplant ) seedlings which make them effective against the diseases which enhance the yield of plants ${ }^{[26]}$.

Nanoscale materials improve tolerance of plants to natural factors, for example, dry season, saltiness and temperatures. In nursery conditions, nanoscale $\mathrm{CeO} 2$ salt was used in canola, the uncovered plants developed apoplastic root boundaries and had upgraded photosynthetic yield ${ }^{[27]}$. Carbon-based nanomaterials can enhance germination and biomass ${ }^{[28]}$.

A few examinations report that nano molecule cointroduction can diminish heavy metal and organic pollutants accumulation in crops ${ }^{[29]}$. The main focus on the application and preparation of agrochemical depends upon the risk evaluation. There are different proposals and capital investment in the development of new technologies ${ }^{[30]}$.

Nanotechnology plays an essential role in the agrifood system for packaging and long term preservation providing means for sustainable food production, and pathogens control, enabling food preservation, thereby minimizing food wastage ${ }^{[31]}$.

\subsection{Soil and Crop Management Strategies}

There are different practices which are used for the production of crops by the use of chemicals; fertilizers but these practices have a negative effect on the environmental conditions that's why there is need of the new practices which play an essential role in high production of the crop as well as they have eco-friendly nature ${ }^{[32]}$. In this way, consideration must not be paid to shielding soil from disintegration (which straightforwardly prompts land deficiencies).

Soil disintegration and land debasement are primary dangers to biological system administrations and horticultural profitability, and such loss in capital resources mostly happens in semi-dry and tropical locales, where agronomic sources are low, and vegetation spread is poor. The disintegration of soil by water and wind is

DOI: https://doi.org/10.30564/jrb.v2i4.2325 
vital procedures changing the surface structure of bare soil by which soil is lost, which impedes soil fruitfulness and results in unreasonable agriculture ${ }^{[33]}$.

Different Soil and crop management strategies or other moderating alternatives have been identified and rehearsed by researchers for the ideal utilization of asset with natural control. All these soil and crop management strategies intend to improve crop efficiency and diminish crumbling of land by improving different attributes of soil, for example, its nature, physical substance and hydrological properties ${ }^{[34]}$.

These strategies keep the balance between supplement information sources and yields through two essential standards:

(1) Matching the information with the crop of interest.

(2) Synchronization between crop development and application timing.

These soil and crop management strategies upgrade the yield of crops and simultaneously save soil assets, thereby securing the environment. Different efforts are being made for the management of soil and crop for providing balanced nutrients, improving soil fertility and improving both soil and crop system which have longterm effects. Furthermore, these techniques reduce the uses of chemicals, fertilizers and also reduce emissions of greenhouse gases, consequently protecting the environment ${ }^{[35]}$.

\subsection{For Sustainable Crop Production and Disease Control Management Technique}

Numerous specialists have recommended that disruption in agro environments is because of changes in harvesting and farming practices since World War II especially with the utilization of agrochemicals ${ }^{[36]}$. Soil is the primary medium for the production of crops. Besides the state of soil also have a negative effect on yields of the crop by causing disease in crops. High or low factors of soil and plants are the leading cause of the production of diseaseborne crops directly or indirectly.

Soil physical properties, for example, temperature, dampness and structure have been found to influence soilborne diseases through soil compaction, seepage and soil temperature. That is why there is need of proper integrated soil crop disease control management techniques which play a role in an assortment of natural materials, for example, fertilizer, excrement, can be utilized to improve soil structure, food web and mineralization of supplements in the root zone to oversee crop sicknesses in all cropping frameworks. A relative investigation of field soils from natural and regular farms is expected to take into account organically, physical, and compound properties of soil and their effect on plant diseases through (IPM) integrated pest management program ${ }^{[37]}$.

Microbes play a significant role by altering the physiology and development of plants. Although some members of rhizosphere microbiome are advantageous to plant development but still plant pathogens can frequently disrupt the root framework by surpassing defensive microbial shield in the rhizosphere and can overcome the intrinsic plant defence systems ${ }^{[38]}$.

Soil-borne pathogens inhabit rhizosphere of the majority of crop plants. Attention is being paid to them because of their ability to destroy crops affecting yield and quality. A few parasitic pathogens (Fusarium, Verticillium, Alternaria, Phytophthora, Didymella, Rhizoctonia, Sclerotium, Pythium, and Rhizopus) are most prevalent in soil and responsible for most of the diseases ${ }^{[39]}$.

Soil-borne pathogens produce diseases in different parts of plants by decreasing the transport of water and nutrient to these parts; therefore, cause damage and affect the quality of plant and crops. IPM (integrated pest control management) is a technique which is used to an enhanced natural mechanism of pest control and production of healthy crops without affecting agro environments. Three main components of IPM are development, checking and anticipation ${ }^{[40]}$.

\subsection{Sustainable Remediation Techniques}

Pesticides are being used in agribusiness and are meant for protecting crops for long terms. Pesticide application is considered the best method for plant crop protection. ${ }^{[41]}$ However, $1 \%$ of applied pesticide kills target while rest of it kills other non-target insects present as well as humans and other plants.

80 to $90 \%$ of pesticides that are applied to crops affect non-target vegetation and can also enter the air and soil. About $80 \%$ of every single applied pesticide could be recognized, with half of these buildups found as change items (TPs) with an industriousness of over ten years.

There are following remediation techniques.

(1) Ex-situ strategy, in which sullied soil is unearthed and shipped to another area for treatment.

(2) On location, in which polluted soil is treated to recover its original state.

In situ, in which damaged is treated without digging the polluted soil.

The selection of methods depends upon contamination of soil ${ }^{[42]}$. Ex-situ strategy was utilized as a soil remediation technique earlier, but it has a few drawbacks, including the significant expense of soil exhuming and transport. Owing to this, in situ strategy has become a method of choice ${ }^{[43]}$. Soil remediation techniques 
are chemical, physical and biological and include bioremediation, phytoremediation and chemical oxidation.

On the one hand, pesticides protect crops against pests, but on the other hand, they contaminate the soil. These pesticides are mixed with food and have a negative effect on the environment and human health. Therefore there is a need for degradation of these pesticides from the soil by using different techniques of remediation. Different soil microbes play an essential role in the degradation of soil contamination through the process of bioremediation or phytoremediation. Mostly in-situ remediation is used for removal of pesticides. As pesticide has a harmful effect on growth as well as productivity of crop is reduced so for better crop yield and soil fertility, phytoremediation and bioremediation are used as an alternative of chemicals and physical techniques for removals of these contaminants ${ }^{[44]}$.

\subsection{Role of Different Microbial Management Strategies}

Different microbial species are used for improvement in soil structure, fertility and quality. Association between plants and the soil microbes is used for removal of toxins, therefore, purifying the soil.

\subsubsection{Plant Growth-promoting Bacteria}

It has been assessed that a milligram of soil contains around 90-100 million microbes with most of these living beings being situated around the base of plants. This reflects that plant roots emit a large amount of carbon that they fix during photosynthesis, and soil organisms use this carbon as a food source. The interaction between plant and soil microbes might be beneficial, harmful or does not affect either of them. Microscopic organisms that are beneficial for plant development and advancement are generally called plant development advancing microbes (PGPB). Due to interactions of these bacteria and fungi, many researchers utilized them in the field of agriculture and for environmental decontamination purposes ${ }^{[45]}$. PGPB may encourage plant development either directly or indirectly. Direct advancement of plant development occurs when PGPB supply nutrients from the earth, including nitrogen, iron, and phosphate, or balance levels of plant hormones. In the Indirect method, these microbes protect plants against plant pathogens. Due to the rapid increase in population supply does not fulfil the demand of population so in order to increase food production chemicals methods are being replaced with eco-friendly methods that are also more cost-effective ${ }^{[46]}$.

\subsubsection{Soil and Root Related Bacteria}

These yield systems antagonistically influence type and physiology of valuable soil-and root-related micro-biota. The subsequent loss of soil structure reduced water and nutrient supply negative effect on soil richness and its tendency to support plant growth. Protection is conferred by abundant glycoprotein and glomalin, delivered by root mycorrhizal organisms ${ }^{[47]}$.

\subsubsection{Microbial Inoculants}

Microbial vaccination is one of the significant horticultural practices that have been utilized to achieve the desired texture of the soil. Microbial inoculants are advantageous living microorganisms that when added to the soil, improve the accessibility of nutrients subsequently improving plant's development ${ }^{[48]}$. The vast majority of microorganisms that are utilized for the production of microbial inoculants possess the ability to inhabit soil to perform desired tasks. Microbial inoculants are applied, independently or in blends, to seeds, plants and soil to upgrade their efficiency. Microbial inoculants have offered eco-accommodating control system against plant pathogens. Microbial inoculants produce auxiliary antifungal metabolites. These inoculants act as a bio-control agent against disease. These inoculants can tolerate stress conditions, whereas other chemical fertilizers effect soil conditions. Different inoculants are used in combination with other fertilizers or other strains of microbes which play a role in the improvement of soil quality, its structure, growth of the plant, make the plant resistant to other factors and help to produce crops in high yield ${ }^{[49]}$.

\subsubsection{Plant-growth-promoting Rhizobacteria}

Beneficial microbial association improves plant stature, development, accessibility of nutrients, osmosis and also enhance efficiency of plant against a few infections causing microorganisms ${ }^{[50]}$. Different processes, for example, development, differentiation, advancement, and stomatal development, are additionally directed by phytohormones ${ }^{[51]}$. It is found that two or more than two hormones are acting together. The effect of these hormones delivered by PGPR can stimulate or hinder the plant's development. Plant hormones are the most pivotal development controllers; they are known for having a significant impact on plant's auxiliary digestion and are also has a real job in the initiation of plant defence response against stresses. One of the systems for improvement of plant development and stress resistance by beneficial microorganisms is their capacity of phytohormone combination in the rhizosphere or root tissue.

DOI: https://doi.org/10.30564/jrb.v2i4.2325 
Ongoing reports recommend that PGPR upgrade the resilience of plants to abiotic stresses, for example, chilling injury. Plant development can be restrained by different factors like salt, dry season, toxic metals, flood, pathogens, temperature etc. Stress resistant PGPR can limit these factors by utilizing different mechanisms, for example, phosphate solubilization, nitrogen fixation, ACC deaminase creation, and siderophore creation.

PGPR can affect the plant in two different ways either directly by the release of phytohormones or indirectly by. The direct method involves the production of phytohormones, fixation of organic nitrogen and phosphate solubilization. The indirect mechanism involves protecting against phytopathogens by the synthesis of HCN, siderophores, anti-infection agents, unstable metabolites, and smelling salts etc. Utilization of PGPR in horticulture has improved dramatically in different parts of the world to decrease the usage of manure and pesticides. Stress tolerant PGPR is multifunctional involved in the improvement of harvest yield, control of natural contamination, condition eco-accommodating under practical advancement through an assortment of components like activating nitrogen fixation, phosphate solubilization, giving development hormones, siderophores, osmotic reaction, and supplements and going about as biocontrol specialists. The use of these microbes reduces the use of the chemicals and other fertilizers. They also play an essential role in the improvement of soil nutrients ${ }^{[52]}$.

\subsubsection{Bacterial Endophytes}

The interrelationship of every single living thing on earth is considerably more clear in plants world. The plant exists in associations with microorganisms. The connection between plant host and different microorganisms is often beneficial. There are epiphytic, rhizospheric and endophytic microorganisms that occupy the different ecological localities. Amongst these species of microorganisms that exist in profitable relationship with their plant, endophytes have the strongest association than others. Endophytes can be essentially defined as microbial structures that colonize plant tissues without bringing about any unfriendly effect ${ }^{[53]}$. These endophytic microbes benefit their host plants by helping them to develop resistance against biotic and abiotic stress ${ }^{[54]}$. They promote the plant's development. Different investigations have suggested the utilization of endophytic microscopic organisms as bio-inoculants to accomplish a practical, eco-accommodating agrarian development framework.

Distributed under creative commons license 4.0

\subsubsection{Fungal Endophytes}

Fungal endophytes have beneficial relationship with plants, offers biological help to host plants to endure biotic and abiotic stresses. Endophytes get nutrients. They colonize in tissues of, for example, stems, natural products, flowers, roots, leaves and branches; this is asymptomatically.

Endophytic microscopic organisms transmitted in different ways plan or soil to plant, vertically (parent plant to seed), or in a blended way. Most parasitic endophytes are vertically transmitted through the seed ${ }^{[56]}$.

Additionally, these microorganisms enhanced production of nutrients in the plant by utilizing different systems. Such techniques separate inorganic supplement from dirt and absorbed by host plant for the production of proteins and other secondary metabolites. They played a role to improve efficiency by protecting plants from other pathogens for producing significant phytohormones by influencing the physiology of the host plant ${ }^{[57]}$.

\section{Management Practices}

Different management practices were used to improve soil conditions for sustainable production.

\subsection{Tillage Practice for the Improvement of Soil Conditions}

Condition of the soil is changed for tillage. Culturing either releases or compacts the dirt and changes its volume and mass relationship. One property of soil is probably going to change by culturing is mass thickness. Lessening mass thickness becomes penetrable and macropores. In this way, every single physical boundary influencing seedling development and root development, for example, soil wetness, air circulation, temperature and entrance obstruction are influenced by the culturing.

\subsection{Mulching Practice for the Improvement of the Soil Conditions}

Mulch implies a layer of unique material isolating the dirt surface from the air, and mulching is the counterfeit utilization of mulch, to get the changed physical condition. Mulching improves states of substance and soil. Suitable adjustment of the aqueous dirt system, improvement of soil accumulation and impediment of disintegration and soil misfortune, improve the state of soil under mulch. Mulching well impacts the dirt dampness system by controlling dissipation from the soil surface, improving penetration and soil dampness maintenance and encouraging.

DOI: https://doi.org/10.30564/jrb.v2i4.2325 
Mulch impacts the warm dirt system and fluctuates soil atmosphere, mulch materials utilized and pace of utilization. It enhanced soil temperature during cold climate and diminished it during hot. Mulching improves auxiliary soil properties straightforwardly and in a roundabout way by advancing the natural movement. Natural mulching improves porosity and means weight distance across of water-stable totals, due to natural issue decayed by soil microorganisms. The mean weight distance across of water-stable totals increments with increment in the mulch rate ${ }^{[58]}$.

\section{Personal Analysis}

From my point of view, there is need of complete understanding and mechanisms of techniques which are mentioned above, in this study, horizontal gene transfer used for the transfer of genetic materials to plants and microbes. Due to this transfer of genes evolution occurred in genome of plants and microbes which make them more resistant to environmental conditions or factors including stress and others make it more fertile that is necessary for food or crop production. Discuss those technologies which play the role for improvement of soil structure. Because when the soil medium is healthy, the healthy plants were grown and the production of crop or food in high yield with high quantity and quality. Different techniques needed for improvements. Because the population of humans are increasing day by day and food demands are also increased. That is why to meets the future demands of food, more innovative techniques are needed in the more effective agriculture sectors, less time consuming and eco-friendly to the environment. Genetically modified plants and microbes reduced the need for different chemical and pesticides, which have an adverse effect on soil condition. Use of new nanotechnology which is significant, through this technology production of resistance plants by nano agrochemicals, have no adverse effect on environment and nanosensor for sensing the effects of a plant due to undesirable factors like pathogen. However, there is a need for more knowledge for exploring this technique. The techniques which are used in this paper are not enough more techniques needed for the production of sustainable soil and food.

\section{Conclusion}

The increasing population have more demands for food. However, in present condition, due to shortage of land, soil infertility problems and for solutions of these problems different fertilizers, chemicals and pesticides are used for soil and plant growth, but these organic matters have a negative effect in soil condition and produced soil pollution. Different techniques used for the improvement of soil and food production in which genetically modified technique is used for the production of genetically modified plants and microbes through horizontal gene transfer which is used for the transfer of the genetic materials and the production microbes and plants which are resistance to pathogen disease. This technique provides an option for improving the stability of plant disease management. Nanotechnology is the use of nanoparticles of agrochemicals and nanosensors which are used for sensing undesirable conditions and production of yields which are effective against the disease. This technology also has importance for safety opportunities for food. Soil and crop management techniques used for better soil conditions by providing essential balanced nutrient supplements. Integrated pest management is used for improved soil structure and food web. Sustainable remediation techniques are used for decontamination of soil pollution by use of bio and phytoremediation which have more importance in agriculture sectors Different microbial strategies used for the use of the different microbes and microbial inoculants which are used for the enhancement of soil and plant conditions by reducing the stress. Improvement of soil conditions by using tillage and mulching management practices that will be helpful for better soil fertility, which is the primary medium for the production of the high yield crops.

\section{References}

[1] Lobell DB, Burke MB, Tebaldi C, Mastrandrea MD, Falcon WP, Naylor RL. Prioritizing climate change adaptation needs for food security in 2030. Science, 2008, 319(5863): 607-610.

[2] Borlaug N. Feeding a hungry world. In: American Association for the Advancement of Science, 2007.

[3] Kiers ET, Leakey RR, Izac A-M, Heinemann JA, Rosenthal E, Nathan D, Jiggins J. Agriculture at a crossroads. Science-New York Then Washington-, 2008, 320(5874): 320.

[4] FAO F. The future of food and agriculture-Trends and challenges. Annual Report, 2017.

[5] Tilman D, Balzer C, Hill J, Befort BL. Global food demand and the sustainable intensification of agriculture. Proceedings of the national academy of sciences, 2011, 108(50): 20260-20264.

[6] Faostat. FAO Statistical Pocketbook 2015 World Food and Agriculture. In: FAO Rome, 2015.

[7] Pimentel D. Soil erosion: a food and environmental threat. Environment, development and sustainability, 2006, 8(1): 119-137.

[8] Bossio D, Geheb K, Critchley W. Managing water by 
managing land: Addressing land degradation to improve water productivity and rural livelihoods. Agricultural Water Management, 2010, 97(4): 536-542.

[9] Owen D, Williams AP, Griffith GW, Withers PJ. Use of commercial bio-inoculants to increase agricultural production through improved phosphrous acquisition. Applied Soil Ecology, 2015, 86: 41-54.

[10] Trivedi P, Pandey A, Palni LMS. Bacterial inoculants for field applications under mountain ecosystem: present initiatives and future prospects. In. Bacteria in agrobiology: Plant probiotics. Springer, 2012: 1544.

[11] Carvajal-Muñoz J, Carmona-Garcia C. Benefits and limitations of biofertilization in agricultural practices. Livestock Research for Rural Development, 2012, 24(3): 1-8.

[12] Zechner E, De La Cruz F, Eisenbrandt R, Grahn A, Koraimann G, Lanka E, Muth G, Pansegrau W, Thomas C, Wilkins B. Conjugative-DNA transfer processes. The horizontal gene pool: bacterial plasmids and gene spread, 2000, 23: 419

[13] Ochman H, Lawrence JG, Groisman EA. Lateral gene transfer and the nature of bacterial innovation. Nature, 2000, 405(6784): 299-304.

[14] Wang Y, Xiao M, Geng X, Liu J, Chen J. Horizontal transfer of genetic determinants for degradation of phenol between the bacteria living in plant and its rhizosphere. Applied Microbiology and Biotechnology, 2007, 77(3): 733-739.

[15] Maheshwari M, Abulreesh HH, Khan MS, Ahmad I, Pichtel J. Horizontal gene transfer in soil and the rhizosphere: Impact on ecological fitness of bacteria. In. Agriculturally Important Microbes for Sustainable Agriculture. Springer, 2017: 111-130.

[16] Heinemann JA, Traavik T. Problems in monitoring horizontal gene transfer in field trials of transgenic plants. Nature Biotechnology, 2004, 22(9): 11051109.

[17] Vincelli P. Genetic engineering and sustainable crop disease management: opportunities for case-by-case decision-making. Sustainability, 2016, 8(5): 495.

[18] Beura K, Rakshit A. 2013. Bt cotton influencing enzymatic activities under varied soils. Open Journal of Ecology, 2013.

[19] Kunito T, Ihyo Y, Miyahara H, Seta R, Yoshida S, Kubo H, Nagaoka K, Sakai M, Saeki K. Soil properties affecting adsorption of plasmid DNA and its transformation efficiency in Escherichia coli. Biology and Fertility of Soils, 2016, 52(2): 223-231.

[20] Morrissey EM, McHugh TA, Preteska L, Hayer M, Dijkstra P, Hungate BA, Schwartz E. Dynamics of extracellular DNA decomposition and bacterial com- munity composition in soil. Soil Biology and Biochemistry, 2015, 86: 42-49.

[21] Cai P, Huang Q, Chen W, Zhang D, Wang K, Jiang D, Liang W. Soil colloids-bound plasmid DNA: effect on transformation of E. coli and resistance to DNase I degradation. Soil Biology and Biochemistry, 2007, 39(5): 1007-1013.

[22] Mandal A, Sarkar B, Owens G, Thakur J, Manna M, Niazi NK, Jayaraman S, Patra AK. Impact of genetically modified crops on rhizosphere microorganisms and processes: a review focusing on Bt cotton. Applied Soil Ecology, 2020, 148: 103492.

[23] Cui Y, Wei Q, Park H, Lieber CM. Nanowire nanosensors for highly sensitive and selective detection of biological and chemical species. Science, 2001, 293(5533): 1289-1292.

[24] Elmer WH, White JC. The use of metallic oxide nanoparticles to enhance growth of tomatoes and eggplants in disease infested soil or soilless medium. Environmental Science: Nano, 2016, 3(5): 10721079.

[25] Rossi L, Zhang W, Ma X. Cerium oxide nanoparticles alter the salt stress tolerance of Brassica napus $\mathrm{L}$. by modifying the formation of root apoplastic barriers. Environmental Pollution, 2017, 229: 132-138.

[26] Pandey K, Lahiani MH, Hicks VK, Hudson MK, Green MJ, Khodakovskaya M. Effects of carbon-based nanomaterials on seed germination, biomass accumulation and salt stress response of bioenergy crops. PloS one, 2018, 13(8): e0202274.

[27] Deng R, Lin D, Zhu L, Majumdar S, White JC, Gardea-Torresdey JL, Xing B. Nanoparticle interactions with co-existing contaminants: joint toxicity, bioaccumulation and risk. Nanotoxicology, 2017, 11(5): 591-612.

[28] Kah M, Tufenkji N, White JC. Nano-enabled strategies to enhance crop nutrition and protection. Nature nanotechnology, 2019, 14(6): 532-540.

[29] Rodrigues SM, Demokritou P, Dokoozlian N, Hendren CO, Karn B, Mauter MS, Sadik OA, Safarpour M, Unrine JM, Viers J. Nanotechnology for sustainable food production: promising opportunities and scientific challenges. Environmental Science: Nano, 2017, 4(4): 767-781.

[30] Germer J, Sauerborn J, Asch F, de Boer J, Schreiber J, Weber G, Müller J.. Skyfarming an ecological innovation to enhance global food security. Journal für Verbraucherschutz und Lebensmittelsicherheit, 2011, 6(2): 237.

[31] Powlson DS, Gregory PJ, Whalley WR, Quinton JN, Hopkins DW, Whitmore AP, Hirsch PR, Goulding KW. Soil management in relation to sustainable ag- 
riculture and ecosystem services. Food policy, 2011, 36: S72-S87.

[32] Keesstra S, Pereira P, Novara A, Brevik EC, Azorin-Molina $\mathrm{C}$, Parras-Alcántara L, Jordán $\mathrm{A}$, Cerdà A. Effects of soil management techniques on soil water erosion in apricot orchards. Science of The Total Environment, 2016, 551: 357-366.

[33] Dumanski J, Peiretti R. Modern concepts of soil conservation. International soil and water conservation research, 2013, 1(1): 19-23.

[34] Esilaba AO, Byalebeka J, Delve RJ, Okalebo J, Ssenyange D, Mbalule M, Ssali H. On farm testing of integrated nutrient management strategies in eastern Uganda. Agricultural systems, 2005, 86(2): 144-165.

[35] Shah F, Wu W. Soil and crop management strategies to ensure higher crop productivity within sustainable environments. Sustainability, 2019, 11(5): 1485.

[36] Altieri MA, Nicholls CI. Soil fertility management and insect pests: harmonizing soil and plant health in agroecosystems. Soil and Tillage Research, 2003, 72(2): 203-211.

[37] Ghorbani R, Wilcockson S, Koocheki A, Leifert C. Soil management for sustainable crop disease control: a review. Environmental Chemistry Letters, 2008, 6(3): 149-162.

[38] Mendes R, Garbeva P, Raaijmakers JM. The rhizosphere microbiome: significance of plant beneficial, plant pathogenic, and human pathogenic microorganisms. FEMS microbiology reviews, 2013, 37(5): 634663.

[39] Beed F, Benedetti A, Cardinali G, Chakraborty S, Dubois T, Halewood M, Garrett KA. Climate change and micro-organism genetic resources for food and agriculture: state of knowledge, risks and opportunities, 2011.

[40] Dababat AA, Erginbas Orakci G, Toumi F, Braun H-J, Morgounov A, Sikora RA. IPM to control soil-borne pests on wheat and sustainable food production. Arab Journal of Plant Protection, 2018.

[41] Özkara A, Aky1l D, Konuk M. Pesticides, environmental pollution, and health. In. Environmental Health Risk-Hazardous Factors to Living Species. IntechOpen, 2016.

[42] Morillo E, Villaverde J. Advanced technologies for the remediation of pesticide-contaminated soils. Science of The Total Environment, 2017, 586: 576-597.

[43] Wang L, Li F, Zhan Y, Zhu L. Shifts in microbial community structure during in situ surfactant-enhanced bioremediation of polycyclic aromatic hydrocarbon-contaminated soil. Environmental Science and Pollution Research, 2016, 23(14): 14451-14461.

[44] Sun S, Sidhu V, Rong Y, Zheng Y. Pesticide pollu- tion in agricultural soils and sustainable remediation methods: a review. Current Pollution Reports, 2018, 4(3): 240-250.

[45] Glick BR. Beneficial plant-bacterial interactions. Springer, 2015.

[46] Glick BR. Soil microbes and sustainable agriculture. Pedosphere, 2018, 28(2): 167-169.

[47] Sen R. The root-microbe-soil interface: new tools for sustainable plant production. The New Phytologist, 2003, 157(3): 391-394.

[48] Gaind S. Microbial inoculants: an approach to sustainable agriculture. Biotech Article, 2011.

[49] Alori ET, Dare MO, Babalola OO. Microbial inoculants for soil quality and plant health. In. Sustainable agriculture reviews. Springer, 2017: 281-307.

[50] Yang J, Kloepper JW, Ryu C-M. Rhizosphere bacteria help plants tolerate abiotic stress. Trends in plant science, 2009, 14(1): 1-4.

[51] Davies PJ. Plant hormones: physiology, biochemistry and molecular biology. Springer Science \& Business Media, 2013.

[52] Kumar A, Patel JS, Meena VS, Srivastava R. Recent advances of PGPR based approaches for stress tolerance in plants for sustainable agriculture. Biocatalysis and Agricultural Biotechnology, 2019, 20: 101271.

[53] Kandel SL, Joubert PM, Doty SL. Bacterial endophyte colonization and distribution within plants. Microorganisms, 2017.

[54] Bandyopadhyay K, Hati K, Singh R. Management options for improving soil physical environment for sustainable agricultural production: a brief review. Journal of Agricultural Physics, 2009, 9: 1-8.

[55] Li H, Parmar S, Sharma VK, White JF. Seed endophytes and their potential applications. In. Seed Endophytes. Springer, 2019: 35-54.

[56] Lobell DB, Burke MB, Tebaldi C, Mastrandrea MD, Falcon WP, Naylor RL. Prioritizing climate change adaptation needs for food security in 2030. Science, 2008, 319(5863): 607-610.

[57] Miliute I, Buzaite O, Baniulis D, Stanys V. Bacterial endophytes in agricultural crops and their role in stress tolerance: a review. Zemdirbyste-Agriculture, 2015, 102(4): 465-478.

[58] Omomowo OI, Babalola OO. Bacterial and fungal endophytes: Tiny giants with immense beneficial potential for plant growth and sustainable agricultural productivity. Microorganisms, 2019, 7(11): 481. 